Proceedings of the 2011 Winter Simulation Conference

S. Jain, R.R. Creasey, J. Himmelspach, K.P. White, and M. Fu, eds.

\title{
RAPID MODELING OF FIELD MAINTENANCE USING DISCRETE EVENT SIMULATION
}

\author{
Abdullah A. Alabdulkarim \\ Majmaah University \\ School of Engineering \\ Majmaah, SAUDI ARABIA
}

\author{
Peter D. Ball \\ Ashutosh Tiwari \\ Cranfield University \\ School of Applied Sciences \\ Cranfield, MK43 0AL, UK
}

\begin{abstract}
Discrete event simulation has been applied to a wide range of applications areas due to its ability to represent stochastic systems over time. Maintenance, particularly field maintenance, is complex due to the interaction of different sub-systems of use, maintenance, repair and inventory and the conflicting demands of minimizing cost and maximizing availability. The area of simulation of maintenance systems receives little treatment in the literature and tends to focus on reliability modeling of individual assets. The work presented here documents research to fill this gap by specifying, creating and testing simulation functionality to rapidly model field maintenance systems.
\end{abstract}

\section{INTRODUCTION}

The area of asset management is gaining significance especially in the availability contracts. With contract performance including measures concerning the availability of individual assets, effective maintenance is important. Whilst there has been a significant amount of research on reliability modeling of assets in isolation and overall service system design, the literature contains little work on how asset reliability and the provision of maintenance affects the overall performance of a service system.

Simulation is used to model the behavior and subsequent performance of systems over time (dynamically). Simulation has been used extensively for manufacturing systems modeling and increasingly it is used for service systems. However, there is an absence of literature on simulation of maintenance in service systems, especially field maintenance (where maintenance is carried out in remote places, i.e., customer site). Simulation models have been applied to maintenance (e.g., Altuger and Chassapis 2009; Ali et al. 2008) to increase production throughput in the manufacturing systems domain. There is, however, a gap in simulating maintenance for products in use where modeling maintenance activity and performance metrics are more complex.

It would seem intuitive that the more sophisticated the maintenance regime, the higher the asset availability would be and therefore better performance against service contract metrics. As more is known about an asset's performance through increasing levels of asset monitoring it would be expected that the maintenance regime would enable better availability. However, initial investigations have shown this to not always to be the case (Ball et al. 2010). Assets exist within a wider system and it is the performance of other parts of the system that influence availability as well. There has been little work on understanding impact of maintenance of assets in a service system on overall system performance and even less on the use of simulation to support this analysis. Discrete Event Simulation (DES) has been identified as one of the most used techniques in the area of operations management (Pannirselvam et al. 1999).

DES software tools available in the market offer wide variety of entities that would help to build any manufacturing or service system without significant effort. However, current software lacks the logic in building of maintenance systems, especially when diagnostics or predictive maintenance are involved. 
This has motivated this research to create entities with built-in logic to represent different maintenance strategies (Reactive, Preventative, and Diagnostics) to help academics and industrial practitioners to rapidly build maintenance system strategies using simulation.

\section{BACKGROUND}

DES has been used to simulate variety of systems ranging from supply chain (Rytila and Spens 2006), health care (Wang et al. 2009), production systems (Kiba et al. 2009) and construction (Hassan and Gruber 2008).

DES has also been used as a decision instrument in the asset availability. An evaluation on automotive manufacturing performance was performed by Ali et al. (2008) especially in recognizing the bottlenecks and choosing the appropriate policies by means of simulation and optimization. They argued that the majority of production systems at present have unsatisfactory overall availability caused mainly by too much downtime due to machine/component failures and quality issues.

Further, Roux et al. (2008) advocated a new approach that combined optimization algorithms and simulation methods in the effort to evaluate the strategy of maintenance performances for manufacturing systems. Oyarbide-Zubillaga et al. (2008) have opted to focus on the optimization of preventive maintenance in the manufacturing field. Their main objective was finding the optimal frequencies for the preventive maintenance of multi-equipment systems using cost and profit criteria. Finally, Ng et al. (2008) designed a Machine Service Support System (MSSS) to enable a service and maintenance expert to analyze and diagnose disturbances that crop up even at remote locations.

Apart from manufacturing systems, a few papers highlight the maintenance operations beyond the factory boundary. Greasley (2000) designed DES model for a company bidding for the operation of a train maintenance depot. Application of the model has assisted the company in comprehending the operation and the effects of various strategies in meeting the demands of the depot even in constrained situations. Also, a DES model was also created by the Finnish Air Forces in their bid to study the impact of maintenance resources, policies and operating conditions on the availability of aircraft (Mattila, Virtanen, and Raivio 2008). Work on maintenance modeling spans both production and business process as it involves both the movement of material as well as information and decision making.

Modeling maintenance operations is complex and it is not well developed as modeling manufacturing system operations as more sub-systems interact together in a complex fashion. These sub-systems of production, maintenance staff, and spares inventory are typically modeled in isolation. Duffuaa et al. (2001) tried to understand this complex operation by creating a generic conceptual model that can represent the maintenance in manufacturing systems and integrates different modules. Other work created a conceptual framework that integrates maintenance operations in an airlines industry (Duffuaa and Andijani 1999). Those examples were only conceptual and were not modeled using techniques such as simulation that provide the actual behavior. Despite those examples, the literature does not discuss how field asset maintenance affects service performance. Field maintenance will add more complexity to a system than would be the case for the maintenance in manufacturing. This is because availability contracts complexity resulting from location of the asset far from the service provider and spares availability. Maintenance systems modeling (whether production or field) shares only few similarities with production modeling. Whilst machines are modeled and perhaps the movement of staff for large scale assembly, there are number of fundamental differences based on Duffuaa et al. (2001):

- The work may not be pre-planned for maintenance;

- The role of information on system (or asset) state can be crucial;

- There is task uncertainty in maintenance modeling which is not just a simple time variation;

- Tasks in maintenance may start without part availability (diagnosis and simple repairs) but may need parts available for completion (machine part failure).

Agnihothri and Karmarkar (1992) created a single bespoke model to reflect field services operations with reactive maintenance. The simulation literature has not shown the effect of diagnostics/prognostics technologies on asset maintenance operations over reactive maintenance. Ball et al. (2010) developed a 
model of asset maintenance to assess the ability of DES to discern complex operations with three different maintenance scenarios (reactive, diagnostics, and prognostics). However, they created a single bespoke, hypothetical model. It is one of the few models in the literature to simulate field maintenance with integration of all the sub-systems involved in such an operation that adds complexity in modeling.

The bespoke nature of the modeling in the literature is due to the lack of standard maintenance functionality for rapid model building. Whilst simulation modeling tools have standard functionality for modeling multiple breakdown modes of machines and the use of labor to repair the machines the functionality is limited. Modeling tools fail to account for the potential need to replace parts of the machines and therefore the constraints associated with availability of spare parts. Additionally repairs are assumed to be completed on first visit and do not require the use of tooling. Finally, the stock control systems for spares are simplistic and it is difficult to account for stock in maintenance, repair and overhaul (MRO) systems.

Academics and industrial practitioners need functionality to support the rapid creation of reactive, preventative, and diagnostics maintenance models. Currently there are few if any examples of modeling diagnostics and predictive maintenance. Those that exist have used the standard functionality available in software but subject to extensive bespoke model creation which is slow, requires additional verification and high skill level, and cannot be re-used by others.

One means by which rapid modeling in the area can be done is through the creation of generic modeling functionality from which the user selects and configures required capabilities. This paper presents the design and use of built-in logic modules to represent different maintenance strategies using a commercial simulation package.

\section{AIM AND APPROACH}

The aim of this work is to design and demonstrate the use of built-in logic modules for a standard simulation package to model different maintenance operation strategies.

In order to carry out research in the area of maintenance strategies and field maintenance, modeling approaches and modeling software are required. The absence of rapid modeling tools and software functionality makes this challenging and requires time consuming bespoke model creation. The availability of standard functionality would support more efficient research investigation.

Literature in this area is low and lacks sufficient detail on which to base the model building. Empirical investigation is therefore required to capture the requirements for modeling and then build modeling functionality.

In order to have generic modules that would suit majority of simulation practitioners, interviews with experts in the field of simulation, operations management, asset monitoring, and maintenance operations were conducted to gather the generic simulation requirements for field maintenance in terms of input/output of the model and the level of functional detail required to simulate such complex systems. In parallel, maintenance models available in the literature were also analyzed. These two sources were used to form generic simulation requirements for modeling field maintenance.

The developed built-in logic modules are then assessed using a case study to assess their suitability in the rapid creation of models and extraction of model results. The use of the individual modules will be useful in their own right, however, the power comes with the ability to swap in and out different functionality to assess the performance of different scenarios. In turn this can support evaluation of the effectiveness of different maintenance control strategies and investigating the impact of investment in diagnostic technology on maintenance performance metrics.

\section{DESIGN}

The design of rapid maintenance modeling functionality followed the process of ascertaining requirements, application of a specification to prototype modeling functionality and subsequent refinement with test data in preparation for use in practice. 
In order to create maintenance modeling functionality, interviews were conducted with relevant experts in the field with parallel review of the maintenance models that were available in the literature. Experts were drawn from academic and industrial support fields covering simulation, operations management, asset monitoring and maintenance. The results of this effort form the generic requirements for simulating a maintenance system. Figure 1 lists the generic functionality identified, whilst Figure 2 provides the input data to support the creation of such functionality and the results expected from running models containing it.

\begin{tabular}{|l|}
\hline Assets \\
Diagnostic technology \\
Maintenance staff \\
Scheduling \\
Parts and tooling \\
Locations \\
Policies (inspection) \\
Overhaul \\
\hline
\end{tabular}

Figure 1: Generic functionality for simulating field maintenance systems

During the interview and literature analysis stage it was apparent a range of different strategies for field maintenance existed. Simplistically these were reactive maintenance (RM) (also known as traditional maintenance), preventative maintenance (PM) (in which operating data is used to proactively perform maintenance prior to statistically expected failure), diagnostic maintenance (DM) (in which sensing technology is able to provide initial diagnosis of faults that have occurred) and finally condition based maintenance (CBM) (in which machine running data is used to predict faults based on current conditions such as vibration or oil quality). There is overlap between these areas, e.g., DM and PM can be used in combination. Using the requirements gathered, three clusters of functionality were specified and created to represent three maintenance strategies.

The first module created represented RM where the maintenance activity is decided when an asset fails. Then labor travels to the asset to diagnose the fault and then decide if the repair could be done immediately without the need for the spare parts. If spare parts are required to carry out the repair then the labor will travel to the storage points. If spares are not available the labor is available to carry out other activities whilst parts arrive with their arrival based on certain distributions. Once spares becomes available the labor will travel to the asset to install it and making the asset available to operate. Downtime of machines under this scenario is a combination of waiting for labor, parts and tools as well as repair time.

The second module represents the PM where a preventative maintenance will occur even before the asset is down based on the historical failure data of the asset. The maintenance is scheduled according to elapsed time or use data with the expectation that most maintenance events are scheduled and carried out prior to random breakdowns. The aim here is to reduce unexpected breakdown and schedule maintenance when labor and parts are available and thus reduce machine down time due to waiting. Again, as with $\mathrm{RM}$, if spare parts are not available the labor will engage in other activities until the parts arrive. It is assumed that the maintenance scheduling strategy is First in First out (FIFO) as well as failed asset repair has priority over the assets that have maintenance scheduled but are still running.

The third module for DT represents the maintenance activity when the diagnostics technology is used. When the asset is down, installed sensing technology sends feedback information to the maintenance center specifying the failure and therefore requirement for parts and tooling are ascertained prior to labor attending. This reduces delays and increasing the productivity of the labor. It is assumed for modeling purposes that the diagnostic technology is able to detect the faults perfectly. 


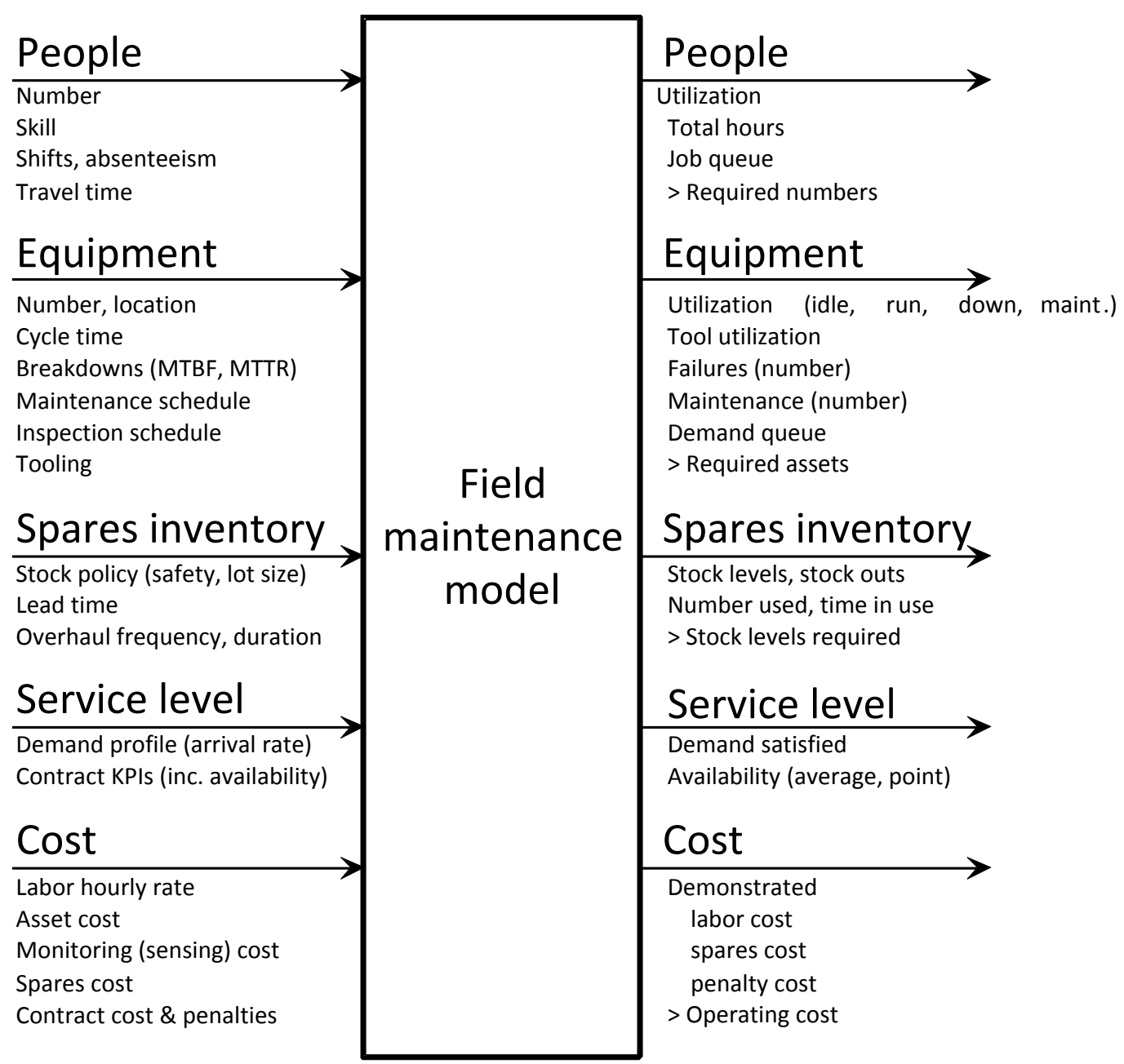

Figure 2: Generic input/output requirements for simulating field maintenance systems

Each modules consist of complex maintenance sub-systems that are integrated including assets, labor, locations (for travel distance), inventory of spares, ordering systems, tooling and possibly sensing technology. As would be expected for simulation modeling, the appropriate model parameters can be stochastic (asset demand, asset cycle times, breakdowns, repair times, order lead times).

Results available include those available as standard in simulation software as well as detailed activities: down time of an asset waiting for diagnosis, waiting spares, waiting repair, and repair time.

The built-in logic modules were created within the standard modeling environment of the Witness simulation package from Lanner Group (Lanner Group 2011). Witness was selected due to its availability within the research group and there were no obvious functionality advantages of using other commercially available software. The functionality was created as modules available from the library by dragging across the relevant icon (RM, PM, DM). Each icon was actually a module that contained a group of machines to collectively represent the functionality required. On insertion into the model the module could be configured as standard for any simulation package by using the standard built-in dialogues to setting up the different breakdowns, cycle times, etc. 
In order to assess the capabilities of the modules created, a case study of assets in different locations was devised. The purpose was twofold. First, the case study would test the ease of use of the modules in different maintenance strategies, and second the case study would provide insight to what behavior between the different strategies (RM, PM, DM) could be ascertained through modeling.

The case was devised using data to stretch the modeling capabilities and uncover different overall behavior. Different numbers of assets $(10,13$, and 15) have been simulated for five years on different maintenance strategy (Reactive, Preventative, Diagnostics) and different labor levels (1 labor, and 2 labor) using same input data. The demand for the asset use was proportional to the number of assets available. This in turn means for a given scenario, increasing the assets increases the activity overall and creates greater demand on the labor for repair and maintenance.

Figure 3 shows a screen shot of the diagnostics scenario with one labor. This model was created quickly by dragging built-in logic functionality from the library window of Witness into the model building area. These could be readily duplicated to represent fleets of assets. Potentially multiple fleets of assets could be created. Parameters were changed to reflect the desired level of reliability, labor levels, etc and the models were run. The run time was not significantly affected by the number of assets contained in each model.

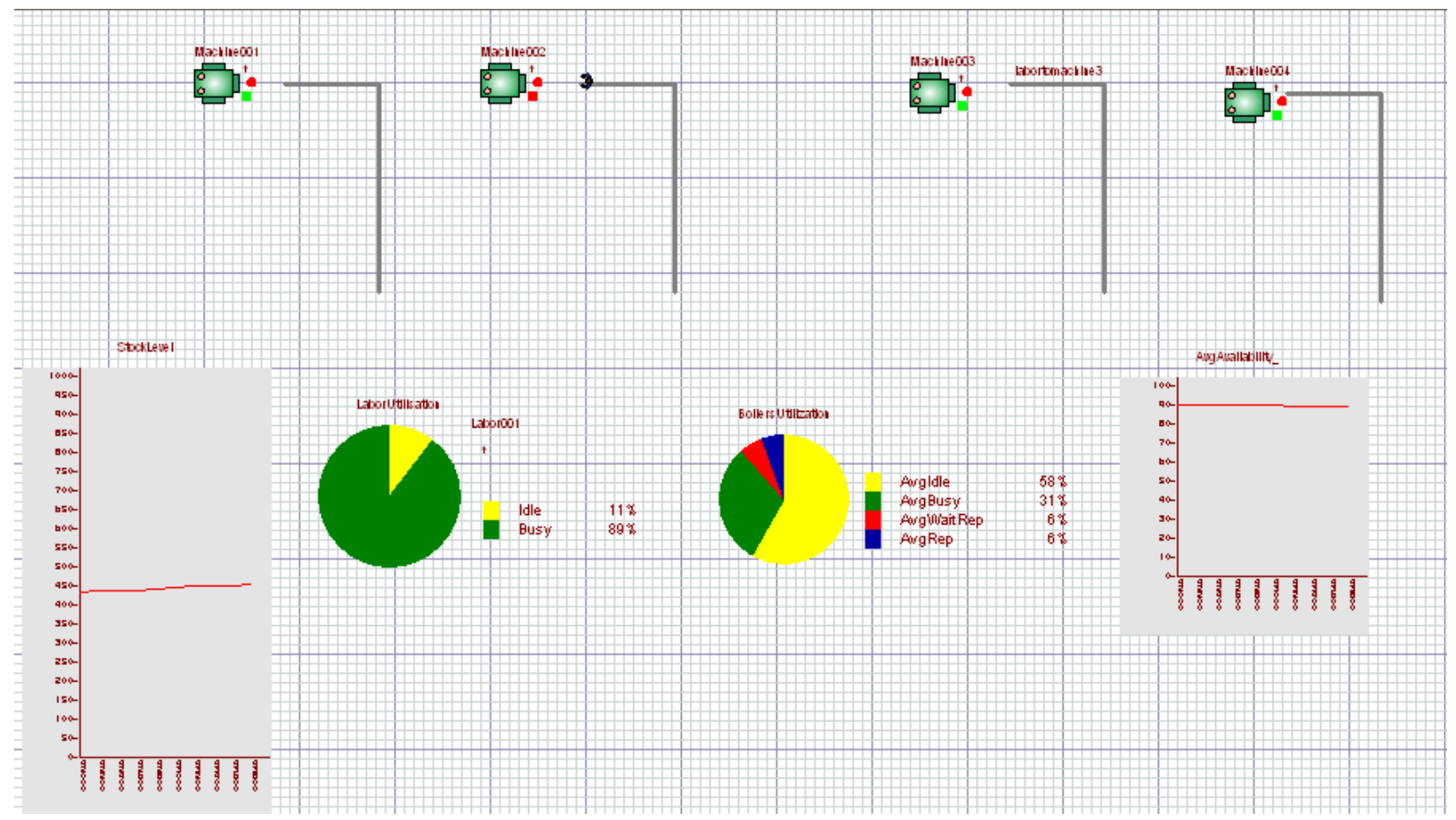

Figure 3: Screen shot of a model of diagnostic maintenance strategy

\section{RESULTS}

The example used shows the ability of DES to model complex operations such as field maintenance, as well as using DES as a decision tool to decide what maintenance strategy should be implemented.

Figure 4 shows a summary of a number of different scenarios that were run. The three strategies of RM, PM and DM were modeled. For each of these the number of labor was varied. For each experiment the collective activities of the labor and assets were summarized. 


\begin{tabular}{|c|c|c|c|c|c|c|c|c|c|c|c|c|c|c|c|c|c|c|c|c|c|c|}
\hline \multirow{4}{*}{\multicolumn{2}{|c|}{$\begin{array}{l}\text { Labor } \\
\text { Assets }\end{array}$}} & \multicolumn{21}{|c|}{ Simulation run result } \\
\hline & & \multicolumn{9}{|c|}{ Reactive } & \multicolumn{6}{|c|}{ Diagnostics } & \multicolumn{6}{|c|}{ Preventative } \\
\hline & & \multicolumn{3}{|c|}{1 labor } & \multicolumn{3}{|c|}{2 Labor } & \multicolumn{3}{|c|}{3 Labor } & \multicolumn{3}{|c|}{1 Labor } & \multicolumn{3}{|c|}{2 Labor } & \multicolumn{3}{|c|}{1 Labor } & \multicolumn{3}{|c|}{2 Labor } \\
\hline & & 10 & 13 & 15 & 10 & 13 & 15 & 10 & 13 & 15 & 10 & 13 & 15 & 10 & 13 & 15 & 10 & 13 & 15 & 10 & 13 & 15 \\
\hline \multirow{2}{*}{ Labor } & Idle \% & 24 & 12 & 12 & 27 & 11 & 11 & 47 & 30 & 20 & 11 & 1 & 1 & 57 & 42 & 33 & 38 & 24 & 19 & 64 & 53 & 47 \\
\hline & Busy \% & 76 & 88 & 88 & 73 & 89 & 89 & 53 & 70 & 80 & 89 & 99 & 99 & 43 & 58 & 68 & 62 & 76 & 81 & 36 & 47 & 53 \\
\hline \multirow{7}{*}{ Asset } & Idle \% & 26 & 24 & 22 & 47 & 44 & 36 & 53 & 53 & 51 & 58 & 56 & 55 & 61 & 61 & 60 & 55 & 53 & 50 & 59 & 59 & 58 \\
\hline & Busy \% & 14 & 13 & 12 & 26 & 23 & 21 & 28 & 28 & 28 & 30 & 30 & 28 & 32 & 32 & 32 & 29 & 28 & 26 & 31 & 31 & 30 \\
\hline & Wait Repair \% & 54 & 57 & 61 & 15 & 22 & 33 & 6 & 6 & 8 & 6 & 9 & 12 & 1 & 1 & 2 & \multirow{4}{*}{16} & \multirow{4}{*}{19} & \multirow{4}{*}{24} & \multirow{4}{*}{9} & \multirow{4}{*}{11} & \multirow{4}{*}{12} \\
\hline & Diagnose $\%$ & 2 & 2 & 2 & 4 & 4 & 3 & 4 & 4 & 4 & NA & NA & NA & NA & NA & NA & & & & & & \\
\hline & Wait spare \% & 2 & 2 & 1 & 3 & 3 & 3 & 4 & 4 & 4 & NA & NA & NA & NA & NA & NA & & & & & & \\
\hline & Repair \% & 2 & 2 & 2 & 5 & 4 & 4 & 5 & 5 & 5 & 6 & 5 & 5 & 6 & 6 & 6 & & & & & & \\
\hline & Availability \% & 40 & 37 & 36 & 74 & 68 & 58 & 81 & 82 & 79 & 90 & 89 & 88 & 93 & 93 & 93 & 84 & 81 & 76 & 90 & 90 & 88 \\
\hline
\end{tabular}

Figure 4: Summary of results collected

Figure 5 shows that under pre-determined conditions of asset reliability and inventory, the asset availability (idle time plus busy time as a proportion of overall time) varies according to the number of assets deployed, the number of labor and the maintenance strategy and associated technology. It is apparent for this scenario that the RM strategy is offering the lowest availability compared to PM and DM maintenance strategies. Notably, the model used to generate these results was created rapidly using generic functionality developed previously. The results show different levels of performance according to the maintenance system configuration, e.g., for low labor levels diagnostic capability showed improved performance over preventative but at higher labor levels a constraint was removed and diagnostics shows negligible effect.

\section{Availability-vs- Maintenance Strategy}

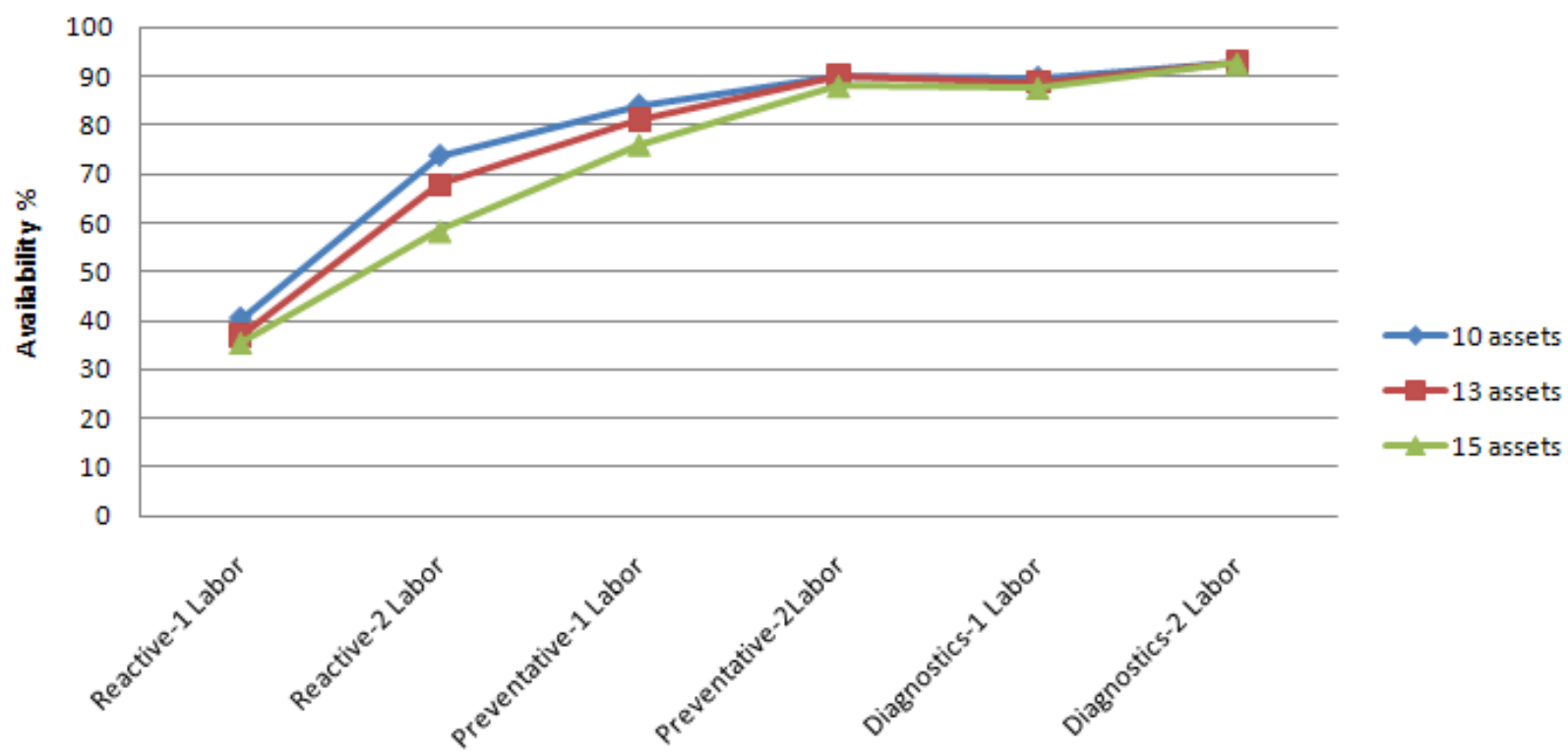

Figure 5: Asset fleet availability vs. maintenance strategy

The scenario created has a number of constraints. It is clear that the reliability has a significant impact on availability and thus the means by which availability is improved will follow those constraints. Improving the labor level here does lead to higher levels of asset availability. Changing the maintenance strategy to be more proactive in detecting or predicting failures is shown to improve availability also. Greater availability of spare parts could reduce wait times, the level of which needs to be assessed to ensure the additional costs of holding the spares provides sufficient benefit in improving uptime. Also, using PM may cost as much as implementing DM technology as the asset maintenance results in a higher level 
of part replacement in order to avoid unplanned downtime. The differences in results show that the cost of different set ups could be compared, e.g., if increasing the labor levels for RM leads to the same levels of availability as could be achieved with lower labor levels and installing diagnostic capabilities.

A number of restrictions and limitations exist in the model and experiments. The location of the labor was fixed in a central location with standard travel time rather than splitting the labor across multiple locations and investigating the distribution of labor, the flexibility of labor and the labor travel time. Increasing the number of assets but maintaining fixed level of overall demand on the assets was not investigated here.

This result cannot be generalized as different input data (spares arrival rate, repair time, location of assets, etc.) might have an effect on which strategy should be implemented as well as the importance of asset availability will play major role in the decision making process.

\section{CONCLUSION}

This work shows the potential that discrete event simulation (DES) has in helping to understand the effect of different maintenance strategies in field maintenance. Such strategies may be simple and reactive response to asset faults or may involve extensive asset sensing to detect faults and provide failure information remotely.

The performance of maintenance regimes is affected by asset use, labor availability, spares availability and provision of accurate fault diagnosis. The interaction of the level of investment in different areas of such maintenance situations gives rise to complexity that only a few tools are capable of providing detailed insight, of which DES is one. The problem with the application of DES currently is that simulation tools have limited support for the analysis of trade offs for such situations.

The work carried out here has been to investigate the requirements for field maintenance analysis, specify and create simulation modeling functionality and test it to demonstrate its utility. The key feature of the work has been to create built-in logic functions that enable rapid modeling of field maintenance strategies.

Future work will be on refining the usability of current functionality, increasing the capabilities of the functionality and testing it on practical scenarios. Areas for further research include how to effectively model prognostic maintenance systems.

\section{REFERENCES}

Agnihothri, S. R., and U. S. Karmarkar. 1992. "Performance Evaluation of Service Territories." Operations Research 40:355-366.

Ali, A., X. Chen, Z. Yang, J. Lee, and J. Ni. 2008. "Optimized Maintenance Design For Manufacturing Performance Improvement Using Simulation." In Proceeding of 2008 Winter Simulation Conference, edited by S. J. Mason, R. R. Hill, L. Mönch, O. Rose, T. Jefferson, and J. W. Fowler, 1811-1819. Piscataway, New Jersey: Institute of Electrical and Electronics Engineers, Inc.

Altuger, G., and C. Chassapis. 2009. "Multi Criteria Preventive Maintenance Scheduling Through Arena Based Simulation Modeling." In Proceeding of 2009 Winter Simulation Conference, edited by M. D. Rossetti, R. R. Hill, B. Johansson, A. Dunkin and R. G. Ingalls, 2123-2134. Piscataway, New Jersey: Institute of Electrical and Electronics Engineers, Inc.

Ball, P. D., A. Tiwari, A. Alabdulkarim, R. Cuthbert, and A. Thorne. 2010. "Using Discrete Event Simulation to Investigate Engineering Product Service Strategies." In Proceeding of $8^{\text {th }}$ International Conference on Manufacturing Research, edited by V. I. Vitanov, and D. Harrison, 318-323. Durham, UK: Durham University.

Duffuaa, S. O., M. Ben-Daya, K. S. Al-Sultan, and A. A. Andijani. 2001. “A Generic Conceptual Simulation Model for Maintenance Systems.” Journal of Quality in Maintenance Engineering 7:207-219. 
Duffuaa, S. O., and A. Andijani. 1999. "An Integrated Simulation model for Effective Planning of maintenance Operations for Saudi Arabian Airlines (SAUDIA)." Production Planning \& Control 10:579-584.

Greasley, A. 2000. " Using Simulation to Assess the Service Reliability of a Train Maintenance Depot." Quality and Reliability Engineering International 16:221-228.

Hassan, M. M., and S. Gruber. 2008. "Application of Discrete-event to Study the Paving Operation of Asphalt Concrete." Construction Innovation 8:7-22.

Kiba, J., S. Dauzère-Pérès, G. Lamiable, and C. Yugma. 2009. "Simulation of Full 300MM Semiconductor Manufacturing Plant With Material Handling Constraints." In Proceeding of 2009 Winter Simulation Conference, edited by Rossetti, M. D., R. R. Hill, B. Johansson, A. Dunkin, and R. G. Ingalls, 1601-1609. Piscataway, New Jersey: Institute of Electrical and Electronics Engineers, Inc.

Lanner Group. 2011. "Witness Software Developers." Accessed October 6. http://www.lanner.com/en/witness.cfm.

Mattila, V., K. Virtanen, and T. Raivio. 2008. "Improving Maintenance Decision Making in the Finnish Air Force Through Simulation.” Interfaces 38:187-201.

Ng, A. H. C., J. Adolfsson, M. Sundberg, and L. J. De Vin. 2008. "Virtual Manufacturing for Press Line Monitoring and Diagnostics." International Journal of Machine Tools \& Manufacture 48:565-575.

Oyarbide-Zubillaga, A., A. Goti, and A. Sancheze. 2008. "Preventive Maintenance Optimisation of Multiequipment Manufacturing Systems by Combining Discrete-event Simulation and Multi-objective Evolutionary Algorithms." Production Planning \& Control 19:342-355.

Pannirselvam, G. P., L. A. Ferguson, R. C. Ash, and S. P. Siferd. 1999. "Operations Management Research : An Update for the 1990s." Journal of Operations Management 18:95-112.

Roux, O., M. A. Jamali, D. A. Kadi, and E. Chatelet. 2008. "Development of Simulation and Optimization Platform to Analyse Maintenance Policies Performance for Manufacturing Systems." International Journal of Computer Integrated Manufacturing 21:407-414.

Rytila, J. S., and K. M. Spens. 2006. "Using Simulation to Increase Efficiency in Blood Supply Chains." Management Research News 29:801-819.

Wang, T., A. Guinet, A. Belaidi, and B. Besombes. 2009. "Modelling and Simulation of Emergency Services with ARIS and Arena. Case Study: the Emergency Department of the Saint Joseph and Saint Luc Hospital." Production Planning \& Control 20:484-495.

\section{AUTHOR BIOGRAPHIES}

ABDULLAH ALABDULKARIM currently works for Majmaah University in Saudi Arabia as a lecturer in the Mechanical Engineering Department. He is also a PhD student at Cranfield University. His research focuses on simulation modeling for service sectors, mainly maintenance. He obtained his MSc in Logistics and Optimization from University of Portsmouth, and his BSc in Industrial Engineering was obtained from King Saud University. His background is from the aerospace industry in aviation maintenance and operations. His email addresses are a.alabdulkarim@mu.edu.sa, a.alabdulkarim@cranfield.ac.uk.

PETER BALL is a Senior Lecturer in Manufacturing Operations at Cranfield University. He received his bachelors in Mechanical Engineering and his $\mathrm{PhD}$ in manufacturing simulation from Aston University, UK. His research interests focus on the design and operation of manufacturing systems and supply chains and how models and modeling techniques support this. He has worked on projects ranging from production improvement to systems implementation and from supply chain diagnostics to sustainable manufacturing. He has published papers in the area of simulation, outsourcing, supply chain management, service systems, e-business and sustainability. He is a chartered member of the IET (Institution of Engineering and Technology), and a fellow of the HEA (Higher Education Academy). His email address is p.d.ball@cranfield.ac.uk. 
ASHUTOSH TIWARI currently heads Cranfield's Decision Engineering Centre and is the academic lead of the university's Doctoral Training Centre in Manufacturing and Materials. He gained his PhD in multi-criteria optimization from Cranfield University, UK. His research focus is on the application of computing techniques to process re-design/optimization. He has more than 100 research publications and was recently awarded the Institution of Mechanical Engineers (IMechE) Thatcher Bros Prize 2009 for the best paper in manufacturing. His email address is a.tiwari@cranfield.ac.uk. 